\title{
Black sea annual and inter-annual water mass variations from space
}

Yildiz, H.; Andersen, Ole Baltazar; Simav, M.; Kilicogul, A.; Lenk, O.

Published in:

Journal of Geodesy

Link to article, DOI:

10.1007/s00190-010-0421-3

Publication date:

2011

Link back to DTU Orbit

Citation (APA):

Yildiz, H., Andersen, O. B., Simav, M., Kilicogul, A., \& Lenk, O. (2011). Black sea annual and inter-annual water mass variations from space. Journal of Geodesy, 85(2), 119-127. https://doi.org/10.1007/s00190-010-0421-3

\section{General rights}

Copyright and moral rights for the publications made accessible in the public portal are retained by the authors and/or other copyright owners and it is a condition of accessing publications that users recognise and abide by the legal requirements associated with these rights.

- Users may download and print one copy of any publication from the public portal for the purpose of private study or research.

- You may not further distribute the material or use it for any profit-making activity or commercial gain

- You may freely distribute the URL identifying the publication in the public portal

If you believe that this document breaches copyright please contact us providing details, and we will remove access to the work immediately and investigate your claim. 


\title{
BLACK SEA ANNUAL AND INTER-ANNUAL WATER MASS VARIATIONS FROM \\ SPACE
}

\author{
H. Yildiz ${ }^{(1)}$, O.B. Andersen ${ }^{(2)}$, M. Simav ${ }^{(1)}$, A. Kilicoglu ${ }^{(1)}$, O. Lenk ${ }^{(1)}$ \\ (1) General Command of Mapping, Tip Fakultesi Caddesi, 06100, Dikimevi, Ankara, Turkey \\ (2) DTU Space. National Space Institute, Juliane Maries Vej 30, 2100, Copenhagen, Denmark
}

Phone: +90 312 5952219, hasan.yildiz@hgk.msb.gov.tr

This study evaluates the performance of two widely used GRACE solutions (CNES/GRGS RL02 and CSR RL04) in deriving annual and inter-annual water mass variations in the Black Sea for the period 2003-2007. It is demonstrated that the GRACE derived water mass variations in the Black Sea are heavily influenced by the leakage of hydrological signals from the surrounding land. After applying the corresponding correction, we found a good agreement with water mass variations derived from steric corrected satellite altimetry observations. Both GRACE and altimetry show significant annual water mass variations of roughly $7 \mathrm{~cm}$ amplitude peaking in May and a semi-annual signal of roughly $3 \mathrm{~cm}$ peaking in June and in December. The amplitude of the annual water mass signal varies significantly from year to year and is significantly larger during 2004-2006 than in 2003 and 2007. This is also in agreement with the steric corrected altimetry.

Keywords: GRACE, Jason-1, Water Mass Variations, Black Sea

\footnotetext{
* The manuscript solely reflects the personal views of the author and does not necessarily represent the views, positions, strategies or opinions of Turkish Armed Forces.
} 


\section{INTRODUCTION}

Since the launch of the GRACE twin satellites, results obtained from the analyses of GRACEbased models have improved the understanding of mass variations and mass transports in the Earth system, which includes processes in the oceans, atmosphere, hydrosphere, cryosphere and geosphere. In spite of numereous results published in recent years (http://www.csr.utexas.edu/grace/publications/citation.html), the quality of GRACE-based models is still the subject of investigation, due to the fact that the ability of GRACE to recover mass variations in a region is of major importance for application to studies such as terrestrial water storage (e.g., Tapley et al. 2004; Wahr et al. 2004) and non-steric sea level change (Chambers et al. 2004; Fenoglio-Marc et al. 2006; Swenson and Wahr 2007).

In this study, we evaluate the ability of two recent GRACE-based models to recover the annual and inter-annual water mass (WM) variations in the Black Sea including the Azov Sea. GRACE-based models from the Center for Space Research at the University of Texas (CSR) and from the Centre National d'Etudes Spatiales and Groupe de Recherche en Géodesie Spatiale (CNES/GRGS) are used. These two GRACE solutions were selected because they are widely used and produced using different techniques. The CSR solutions require destriping, such as with the decorrelation filter used by Swenson and Wahr (2006), and Gaussian smoothing to remove the residual spatial noise after decorrelation filtering (Chen et al. 2008a). However, any smoothing attenuates the signal and introduces a leakage effect from surrounding regions. Consequently an investigation of the optimal choice of the radius for the Gaussian smoothing for the region was carried out. CNES/GRGS constrained GRACE solutions, on the other hand, do not suffer from the striping effect. This is because the CNES/GRGS coefficients have been computed with a constraint towards a mean gravity field that optimally reduces the short-wavelength striping of the solutions (Lemoine et al. 2007). 
Steric corrected Jason-1 satellite altimetry data are used as an independent method of assessing the performance of these two GRACE-based models.

The Black Sea is an interesting study area because it has relatively strong temporal WM variations. Furthermore, altimetry data in the Black Sea can be used as an independent tool for the evaluation of GRACE-based models. The wide drainage area of the Black Sea (Figure 1) covers a large part of Europe and Asia and provides a total fresh water supply of about 350 $\mathrm{km}^{3} \mathrm{yr}^{-1}$ (Ozsoy and Unluata 1998). River runoff affects the physical characteristics of the sea, and is strongly dependent on the hydrological cycle over continental Europe (Stanev et al. 2002). The large river runoff into the Black Sea changes from year to year and has also a semi-annual component. Therefore, not only the annual but also the semi-annual and the inter-annual components of WM variability of the Black Sea are analyzed.

The leakage effect of land hydrology on the WM variations of the Black Sea is initially quantified using a land hydrology model. Subsequently, the leakage effects on the two GRACE solutions are estimated and used to correct them before the WM variations are derived. Finally, the annual, semi-annual and inter-annual variability is quantified and compared with Jason-1 based estimates.

\section{DATA AND PROCESSING}

\subsection{GRACE Level-2 Products}

Our GRACE time series are from the CNES/GRGS Release-02 (RL02) and CSR Release-04 (RL04) solutions. CNES/GRGS solutions include one hundred and seventy-one 10-day gravity field solutions expressed in normalized Spherical Harmonic (SH) geopotential coefficients from degree 2 up to degree and order 50, covering the period from 03 March 
2003 to 29 December 2007. CSR solutions include fifty-seven monthly gravity field solutions for the period March 2003 to December 2007, supplied as normalized SH geopotential coefficients from degree 2 up to degree and order 60. CNES/GRGS solutions are stabilized towards the EIGEN-GRGS.RL02.MEAN-FIELD mean gravity field at each given epoch, with a constraint law that depends on the degree and order of each coefficient (http://bgi.cnes.fr:8110/geoid-variations/README.html). Monthly means from the 10-day solutions are derived by averaging to be consistent with the temporal resolution of the CSR solutions.

The SH coefficients of CSR level-2 monthly solutions from degree 2 up to degree and order 50 are used to be consistent with the CNES/GRGS GRACE solutions. The data are decorrelated by applying a modified version of the Swenson and Wahr (2006) decorrelation filter called P4M6 (Chen et al. 2007; Chen et al. 2008b). For a given SH of order 6 and above, this filter fits a polynomial of order 4 and removes this from even and odd pairs of coefficients. Finally, Gaussian smoothing (Jekeli 1981) is applied. We test various radii for the Gaussian function, from $500 \mathrm{~km}$ to $0 \mathrm{~km}$ in order to evaluate which represents the best agreement wih steric corrected altimetry in the Black Sea.

Since the degree-one coefficients are not part of these GRACE solutions, an estimate of geocenter motion (Swenson et al. 2008) is added to both GRACE solutions to account for the degree-one components of the gravity field. For both GRACE solutions, atmospheric pressure variations over land and ocean tides have been removed using the European Centre for Meteorological Weather Forecasting (ECMWF) model (http://www.ecmwf.int) and the Finite Element Solution 2004 (FES2004) (Lyard et al. 2006) model respectively. Barotropic ocean signals have been removed from CNES/GRGS solutions using the MOG2D-G barotropic ocean model (Carrère and Lyard 2003). The monthly averages of the MOG2D-G barotropic 
ocean model output should in principle be restored in the CNES/GRGS monthly solutions since we are interested in the total ocean mass signal (Lombard et al 2007). However we do not do that because the applied version of the MOG2D-G model does not cover the Black Sea (Lemoine, personal communication, 2009).

The Ocean Model for Circulation and Tides (OMCT) baroclinic model (Bettadpur 2007; Flechtner 2007) have been used to remove non-tidal short-term oceanic mass variations from the CSR RL04 solutions (Bettadpur 2007). In order to make the CSR solutions consistent with CNES/GRGS solutions, the monthly averages of the short-term non-tidal oceanic contribution are restored to CSR solutions using the CSR RL04 GAD products (Bettadpur 2007).

\subsection{Scaling Factors for GRACE Derived WM Variations}

The Black Sea basin-averaged WM variations from the two GRACE solutions are derived using averaging kernels (Swenson and Wahr 2002). The averaging kernel used is constructed by expanding the Black Sea land-sea mask into SH up to degree and order 50 (Figure 2). The mask is defined as 1 at points inside the Black Sea and 0 outside of it.

Various processing steps, such as the truncation of the spherical harmonic expansion, decorrelation filtering and smoothing will tend to reduce the amplitude of the real signal. In order to investigate this, scaling factors were estimated by simulating a uniform $1 \mathrm{~cm}$ synthetic mass signal of the Black Sea, processing it in the same manner as the GRACE solutions and comparing the retrieved signal with the original one. After expanding the synthetic signal into SH up to degree and order 50, we obtained $0.65 \mathrm{~cm}$. Therefore a factor of $1.53(1 / 0.65)$ is used to scale basin-average WM time series of the CNES/GRGS solutions, as 
no further processing is applied. For the CSR solutions, we decorrelate the synthetic signal using the P4M6 filter and apply a Gaussian smoothing. The decorrelation reduces the basin average to $0.56 \mathrm{~cm}$, and the Gaussian smoothing with half-widths of $100 \mathrm{~km}, 200 \mathrm{~km}, 300 \mathrm{~km}$ and $500 \mathrm{~km}$, reduces it further to $0.22-0.53 \mathrm{~cm}$, depending on the filter half-width (Table- 1 ). Therefore, scaling factors given in Table 1 are used for the various filtered CSR solutions. A test of the scaling factor for the Caspian Sea revealed slightly different result than the one of Swenson and Wahr (2007) (2.7 versus 2.4). We believe that the small difference is due to a different land-sea mask and/or a difference in the P4M6 decorrelation filter.

\subsection{Terrestrial Water Mass Variations}

Terrestrial water mass (TWM) variability around the Black Sea exceeds the WM variability in the Black Sea, and any TWM will leak into the sea areas due to the limited degree and order of the SH expansion and the spatial filtering applied. In order to estimate this leakage, monthly TWM variability at one degree resolution is derived from NASA's Global Land Data Assimilation System (GLDAS) (Rodell et al. 2004; http://csr.utexas.edu/research/ggfc/dataresources.html). The Noah land surface model version 2.7.1 (Ek et al. 2003) with observed precipitation and solar radiation included was used. Also, the Climate Prediction Center (NOAA/CPC) land hydrology model was investigated (Fan and Van den Dool 2005), but problems with the land-sea mask rendered this model unrealistic for the Black Sea region.

For consistency, GLDAS data were processed like the GRACE-based models (Swenson and Wahr 2007): GLDAS data were expanded into SH to degree and order 50 for CNES/GRGS solutions and additionally decorrelated using P4M6 filter and smoothed by a Gaussian filter in the context of CSR solutions. 


\subsection{Sea Level Data}

Monthly altimetry data from the Jason-1 satellite for the period from March 2003 to December 2007 were extracted from the Version 3.1 of the Radar Altimeter Database System, applying the standard corrections (Scharroo 2009). The monthly averages of along-track Jason-1 sea level data were spatially averaged over the Black Sea and the Azov Sea. The Jason-1 altimetry tracks covering the Black Sea are depicted with black dots in Figure 3. Note that the inverse barometer (IB) correction was not applied to the altimetry-based sea level data, in order to be consistent with both GRACE solutions that observe the total sea mass signal (Lombard et al 2007).

\subsection{Steric Heights from WOA05 Seasonal Climatology Data}

Steric sea level variations are not associated with WM variations, and in order to determine and remove the steric contribution to the observed altimetric sea level variations, the monthly temperature and salinity data on one degree resolution grids from the World Ocean Atlas 2005 (WOA2005) database are used (Locarnini et al. 2006; Antonov et al. 2006). The steric sea level (SSL $\mathrm{WOA05}_{\text {) }}$ was estimated by integrating the specific volume anomaly from the surface to a depth of $300 \mathrm{~m}$, as Tsimplis et al. (2004) suggested that there is no significant contribution to the specific volume anomaly from water below $300 \mathrm{~m}$ in the Black Sea. Depth contours and grid points used for the $\mathrm{SSL}_{\mathrm{WOA} 5}$ computation are depicted in Figure 3. Due to the $300 \mathrm{~m}$ depth constraint, the averaged steric sea level variation could only be computed from 29 out of the 51 grid points in the Black Sea (Figure 3).

\section{RESULTS}

The leakage effects from the land surrounding the Black Sea are subtracted from the GRACE derived signals. Then, WM variations at annual and semi-annual scales are quantified by fitting a bias, annual and semi-annual terms to the monthly basin-average time series and 
compared with Jason-1 based estimates. A realistic estimate of the magnitude of errors for the WM estimates cannot be provided as we were unable to obtain realistic estimates of the magnitudes of the errors for the GLDAS model and the steric effect.

\subsection{Leakage Effect from the Surrounding Land}

Annual TWM variations from the GLDAS model surrounding the Black and Caspian Seas are presented in Figure 4 corresponding to different GRACE processing strategies, in order to demonstrate the importance of accounting for leakage from nearby TWM especially due to Gaussian smoothing. The figure shows that the TWM signal is considerably larger around the Black Sea than around the Caspian Sea where Swenson and Wahr (2007) obtained the best result using a Gaussian smoothing of $300 \mathrm{~km}$. Consequently, the leakage will increase in the Black Sea with larger smoothing. Figure 4 (a) shows the annual amplitude of TWM variations derived from the original GLDAS data, which ranges up to $10-20 \mathrm{~cm}$ at the southeastern border of the Black Sea. The truncated, decorrelated and smoothed GLDAS data in Figure 4 are not scaled. In order to quantify the leakage effect, the annual amplitudes of the scaled basin-average hydrological leakage are presented in Table 2 and Table 3, corresponding to CNES/GRGS and CSR GRACE solutions, respectively.

Table 2 shows that the effect of smoothing from the truncation of the $\mathrm{SH}$ at degree and order 50 (Figure 4 (b)) generates a small hydrological leakage into the sea. Table 3 shows that the leakage is larger, when decorrelation and a 300-km Gaussian smoothing are applied (Figure 4 (c)). It becomes even larger after a 500-km smoothing is applied (Figure 4 (d)). Therefore, we investigated the optimal radius of Gaussian smoothing for the CSR solutions. Several halfwidths of Gaussian filters $(0 \mathrm{~km}, 100 \mathrm{~km}, 200 \mathrm{~km}, 300 \mathrm{~km}$ and $500 \mathrm{~km})$ were tested. Table 3 compares the annual and semi-annual components of the CSR derived WM estimates and 
Table 4 evaluates them with steric corrected altimetry in terms of RMS difference and temporal correlation. We found that the larger the half-width of the Gaussian filter, the larger the amplitude of the WM variations, and hence the larger the amplitude difference between CSR GRACE and Jason-1 derived WM variations.

The best agreement with Jason derived WM variations was obtained for unsmoothed (but decorrelated) CSR solutions in terms of amplitude, phase of the annuals signals (Table 3) as well as rms difference whereas the temporal correlation was equally high for various filtered CSR solutions (Table 4). Consequently we used the unsmoothed solution for further analyses.

If it was possible to correct for leakage perfectly, the results would not be dependent on the choice of the smoothing radius for the CSR solutions. However our attempts were not very successful, which was partly due to the fact that the GLDAS model does not model groundwater variations whereas GRACE observes the integrated water storage.

\subsection{Water Mass Variations on Annual and Semi-Annual Scales}

The Jason-1 shows an annual amplitude of $6.8 \pm 1.1 \mathrm{~cm}$ peaking in June. The steric sea level from WOA05 has an annual signal with an amplitude of $2.2 \pm 0.9 \mathrm{~cm}$ peaking in AugustSeptember, which agrees well with values of Stanev et al. (2000) who observed an annual amplitude of $2.5 \mathrm{~cm}$ peaking in mid-August calculated from climatic monthly mean heat fluxes. The steric correction reduces the amplitude of the Jason-1 time series slightly and advances the phase by one month. The resulting Jason-1 derived WM signal has an annual amplitude of $6.5 \pm 1.4 \mathrm{~cm}$ peaking in May-June. 
CNES/GRGS WM estimates shows an annual amplitude of $8.2 \pm 1.2 \mathrm{~cm}$ (Table 2) peaking in April (Figure 5 (a)). Isolating the Black Sea WM by correcting for the leakage signal (Figure 5 (a)) from CNES/GRGS yields an annual amplitude of $6.4 \pm 1.3 \mathrm{~cm}$ peaking in May (Table 2 and Figure 5 (c)).

CSR WM estimates have annual amplitudes of $10.7 \pm 1.8 \mathrm{~cm}$ (Table 3) peaking in April (Figure 5 (b)). Removing the leakage signal from the CSR solutions yields an annual amplitude of $7.4 \pm 1.9 \mathrm{~cm}$ peaking in May (Table 3 and Figure $5(\mathrm{c})$ ).

Table 5 compares CNES/GRGS and CSR derived WM estimates with the steric corrected altimetry. There is a fairly good agreement between the both GRACE derived WM estimates and the Jason-1 derived WM signal in terms of both phase and amplitude and furthermore the results are consistent with Stanev et al. (2000) who suggested that river runoff into the Black Sea peaks in May.

The presence of the semi-annual signal is a consequence of a small secondary maximum in December-January observed in both GRACE derived and Jason-1 derived WM time series (Figure 6). This maximum is likely explained by the increased precipitation in fall (Stanev et al. 2000). The Jason-1 derived WM signal has a semi-annual signal with an amplitude of $2.8 \pm$ $1.4 \mathrm{~cm}$ peaking in December-January and June-July. CNES/GRGS and CSR GRACE solutions have semi-annual signals with amplitudes of $2.9 \pm 1.3 \mathrm{~cm}$ and $2.4 \pm 1.9 \mathrm{~cm}$ repectively, both estimates peaking in December-January and June-July. 


\subsection{Inter-Annual Water Mass Variations}

The two GRACE derived WM time series are shown in Figure 6 in comparison with the WM estimated from steric corrected Jason-1 altimetry. The scaled WM time series from the two GRACE based estimates have a temporal correlation of 0.84 with an rms difference of $5.4 \mathrm{~cm}$ with each other. The WM time series from CNES/GRGS and CSR solutions show a good agreement with Jason-1 derived WM (Figure 6) and the temporal correlations are 0.83 and 0.87 with rms differences of $4.6 \mathrm{~cm}$ and $4.80 \mathrm{~cm}$, respectively. Figure 6 also shows that the annual WM varies significantly from year to year. The annual variation is largest in 2004, 2005 and 2006, and significantly reduced in 2003 and 2007. Also the data shows a 10-15 cm drop in WM during the second half of 2007. This drop can potentially be caused by increasing evapotranspiration or reduced precipitation over the river drainage basin during the summer of 2007.

\section{CONCLUSION}

Two widely used GRACE solutions (CNES/GRGS RL02 and CSR RL04) have been compared with steric corrected Jason-1 altimetry for the period 2003-2007 in order to assess their performance in deriving regionally averaged oceanic WM variations at annual and interannual scales in the Black Sea.

The results show that GRACE estimated WM variations in the Black Sea are heavily influenced by the leakage of hydrological signals from the surrounding land. Consequently, the CSR solutions which normally require filtering are more affected by leakage than the CNES/GRGS solutions. GLDAS was applied to study the leakage, but as GLDAS only models the soil moisture signal in the upper 2 meters of soil and ignores WM variations from ground water and surrounding open bodies (e.g. the Mediterranean Sea, etc.) it was 
impossible to precisely quantify and correct for TWM leakage for the Black Sea. Comparison with WM from satellite altimetry led us to prefer the unsmoothed (no Gaussian filtering) decorrelated CSR solutions along with and CNES/GRGS solutions for futher investigation.

Good agreement between both GRACE solutions and the steric corrected altimetry was found in terms of both amplitude and phase. This showed that GRACE can be used to derive water mass variations in the Black Sea and other regions of comparable size, provided that the signal leakage from surrounding regions is corrected for. Both GRACE WM estimates show an annual signal of roughly $7 \mathrm{~cm}$ peaking in May and a semi-annual signal of roughly $3 \mathrm{~cm}$ peaking in June and December. Semi-annual signals in Black Sea WM variations are small but significant, as they modify the shape of the annual signal, creating a secondary maximum in December.

Similarly, the amplitude of the annual signals varies significantly from year to year and is significantly larger during 2004-2006 than in 2003 and 2007. These year-to-year variations in the annual water mass mostly reflect the variations in inflow and outflow of water mass in the Black Sea through nearby rivers and straits as also suggested by Stanev et al. (2000).

Acknowledgement The authors would like to thank J.L.Chen for providing the monthly GLDAS data and P4M6 decorrelation filter program and the CSR and CNES/GRGS teams for preparing GRACE level-2 products. We also thank Pavel Ditmar, Luciana Fenoglio-Marc and three other anonymous reviewers for their constructive comments. 


\section{REFERENCES}

Andersen OB, Knudsen P, Berry P (2010) The DNSC08GRA global marine gravity field from double retracked satellite altimetry, J Geod. Doi:10.1007/s00190-009-0355-9.

Antonov JI, Locarnini RA, Boyer TP, Mishonov AV, Garcia HE (2006) World Ocean Atlas 2005, vol. 2, Salinity, NOAA Atlas NESDIS, vol. 62, edited by S. Levitus, 182 pp, U.S. Gov. Print. Off., Washington, D.C.

Bettadpur S (2007) Level-2 gravity field product user handbook, GRACE 327-734, The GRACE Project, Center for Space Research, University of Texas at Austin.

Carrère L, Lyard F (2003) Modeling the barotropic response of the global ocean to atmospheric wind and pressure forcing - comparisons with observations. Geophys Res Lett 30(6): 1275. Doi:10.1029/2002GL016473.

Chambers DP, Wahr J, Nerem RS (2004) Preliminary observations of global ocean mass variations with GRACE, Geophys Res Lett 31 L13310. Doi:10.1029/2004GL020461.

Chen JL, Wilson CR, Tapley BD, Grand S (2007) GRACE detects coseismic and postseismic deformation from the Sumatra-Andaman earthquake. Geophys Res Lett 34: L13302. Doi:10.1029/2007GL030356.

Chen JL, Wilson CR, Seo, KW (2008a) S2 tide aliasing in GRACE time-variable gravity solutions, J Geod. DOI 10.1007/s00190-008-0282-1.

Chen JL, Wilson CR, Tapley BD, Blankenship D, Young D (2008b) Antartic regional ice loss from GRACE. Earth Planet Sci Lett 266: 140-148. Doi:10.1016/j.epsl.2007.10.057.

Ek, MB, Mitchell KE, Lin Y, Rogers E, Grunmann P, Koren V, Gayno G, Tarpley JD (2003) Implementation of Noah land surface model advances in the National Centers for Environmental Prediction operational mesoscale Eta model. J Geophys Res 108: 8851. Doi:10.1029/2002JD003296.

Fan, Y, van den Dool H (2005) The Climate Prediction Center global monthly soil moisture data set at $0.5 \mathrm{deg}$ resolution for 1948 - present. J Geophys Res 109: D10102. Doi:1029/2003JD004345.

Fenoglio-Marc L, Kusche J, Becker M (2006) Mass variation in the Mediterranean Sea from GRACE and its validation by altimetry, steric and hydrologic fields. Geophys Res Let 33: L19606. Doi:10.1029/2006GL026851.

Flechtner F (2007) GRACE AOD1B Product Description Document for Product Releases 01 to 04 (Rev. 3.1, April 13, 2007), GRACE 327-750, GeoForschungsZentrum Potsdam, Germany.

Jekeli C (1981) Alternative methods to smooth the Earth's gravity field, Techical Report, Department of Geodetic Science, Ohio State University, Columbus, Ohio. 
Lemoine JM, Bruinsma S, Loyer S, Biancale R, Marty JC, Perosanz F, Balmino G (2007) Temporal gravity field models inferred from GRACE data. J Adv Space Res 39: 1620-1629. doi:10.102/j/asr.2007.03.062.

Locarnini RA, Mishonov AV, Antonov JI, Boyer TP, Garcia HE (2006) World Ocean Atlas 2005, vol. 1, Temperature, NOAA Atlas NESDIS, vol. 61, edited by S. Levitus, 182 pp., U.S. Gov. Print. Off. Washington, D.C.

Lombard A, Garcia D, Ramillien G, Cazenave A, Biancale R, Lemoine JM, Flechtner F, Schmidt R, Ishii M (2007) Estimation of steric sea level variations from combined GRACE and Jason-1 data. Earth and Planetary Science Letters, 254, 1-2, 194-202.

Lyard F, Lefevre F, Letellier T, Francis O (2006) Modelling the global ocean tides: modern insights from FES2004. Ocean Dyn 56:394-415. Doi:10.1007/s10236-006-0086-x.

Scharroo R (2009) Radar Altimeter Database System (RADS) Version 3.0 User Manual and Format Specification, Space Res. Organ. Neth. Utrecht, Netherlands.

Ozsoy E, Unluata U (1998) The Black Sea. In: Robinson A, Brink K (eds) The Sea, vol.11, John Wiley, New York.

Rodell M, Houser PR, Jambor U, Gottschalck J, Mitchell K, Meng CJ, Arsenault K, Cosgrove B, Radakovich J, Bosilovich M, Entin JK, Walker JP, Lohmann D, Toll D (2004) The Global Land Data Assimilation System. Bulletin of American Meteorological Society, 85: 381-394. Doi: 10.1175/BAMS-85-3-381.

Stanev EV, Le Traon PY, Peneva EL (2000) Sea level variations and their dependency on meteorological and hydrological forcing: Analysis of altimeter and surface data for the Black Sea. J Geophys Res 105: 17203-17216.

Stanev EV, Beckers JM, Lancelot C, Staneva JV, Le Traon PY, Peneva EL, Gregoire M (2002) Coastal-open Ocean Exchange in the Black Sea: Observations and Modelling. Estuarine, Coastal and Shelf Science 54: 601620.

Swenson, S, Chambers D, Wahr J (2008) Estimating geocenter variations from a combination of GRACE and ocean model output, J Geophys Res 113: B08410.Doi:10.1029/2007JB005338.

Swenson S, Wahr J (2007) Multi-sensor analysis of water storage variations of the Caspian Sea. Geophys Res Let 34: L16401. Doi:10.1029/2007GL030733.

Swenson S, Wahr J (2006) Post-processing removal of correlated errors in GRACE data. Geophys Res Let 33 : L08402. Doi:10.1029/2005GL025285. 
Swenson S, Wahr J (2002) Methods for inferring regional surfacemass anomalies from GRACE measurements of time-variable gravity, J. Geophys. Res,. 107(B9), 2193, doi:10.1029/2001JB000576.

Tapley BD, Bettadpur S, Ries J, Thompson PF, Watkins MM (2004) GRACE measurements of mass variability in the earth system. Science 305:503-505. doi:10.1126/science.1099192.

Tsimplis MN, Josey SA, Rixen M, Stanev EV (2004) On the forcing of sea level in the Black Sea, J Geophys Res 109: 1-13. Doi:10.1029/2003JC002185.

Wahr J, Swenson S, Zlotnicki V, Velicogna I (2004) Time-variable gravity from GRACE: first results. Geophys Res Lett 31:L11501.doi:10.1029/2004GL019779. 


\section{FIGURES}

Figure 1. The Black Sea with its surrounding countries.

Figure 2. The averaging kernel used to obtain basin-average GRACE derived WM variations from the CNES/GRGS and the CSR GRACE solutions.

Figure 3. Water depths of the Black Sea in meters derived from the DNSC08 bathymetry data (Andersen et al. 2010). The $1^{\circ} \times 1^{\circ}$ grid points used for the computation of steric sea level at $300 \mathrm{~m}$ depth are represented by the black triangles. The Jason-1 altimetry tracks covering the Black Sea are depicted with black dots.

Figure 4. Annual amplitude $(\mathrm{cm})$ of the TWM from the GLDAS model a) Original GLDAS data averaged into one degree resolution b) GLDAS data expanded into spherical harmonics ( $\mathrm{SH}$ ) up to degree and order $50 \mathrm{c}$ ) GLDAS data in Figure 4 b), decorrelated using the P4M6 filter and smoothed using the 300-km Gaussian filter d) GLDAS data in Figure 4 b), decorrelated using the P4M6 filter and smoothed using the 500-km Gaussian filter. Note that the GLDAS data presented in this figure are not scaled.

Figure 5. Scaled basin-average time series of the mass variations from GRACE and the leakage effects from GLDAS for (a) CNES/GRGS solutions (b) CSR GRACE solutions after the P4M6 decorrelation filter is applied (c) GRACE derived WM time series obtained after correcting for the leakage effects.

Figure 6. Comparison of scaled GRACE derived and Jason-1 derived basin-average WM time series. Black curve and red curve represent CNES/GRGS based and CSR WM based estimates corrected for leakage effects, respectively. Jason-1 derived WM variations corrected for steric effect are shown in the blue curve. 


\section{TABLES}

Table 1. Scaling factors used for CSR solutions that are decorrelated and smoothed with Gaussian filters of varying half-widths.

\begin{tabular}{|c|c|}
\hline $\begin{array}{c}\text { Half-width of } \\
\text { Gaussian Filter } \\
(\mathrm{km})\end{array}$ & Scaling Factor \\
\hline 0 & $1.78(1 / 0.56)$ \\
\hline 100 & $1.89(1 / 0.53)$ \\
\hline 200 & $2.22(1 / 0.45)$ \\
\hline 300 & $2.79(1 / 0.36)$ \\
\hline 500 & $4.59(1 / 0.22)$ \\
\hline
\end{tabular}

Table 2. Annual and semi-annual amplitudes and phases of the CNES/GRGS GRACE mass time series, GLDAS WM time series and the GRACE derived WM time series (CNES/GRGS-GLDAS) obtained after correcting the basin-average of CNES/GRGS GRACE mass time series for the leakage signal. The results presented in this table are obtained from the scaled basin-average time series.

\begin{tabular}{|c|c|c|c|c|}
\hline \multirow{2}{*}{ Basin-average Time Series } & \multicolumn{2}{|c|}{ Annual Signal } & \multicolumn{2}{c|}{ Semi-annual Signal } \\
\cline { 2 - 5 } & $\begin{array}{c}\text { Amplitude } \\
(\mathrm{cm})\end{array}$ & $\begin{array}{c}\text { Phase } \\
(\text { days })\end{array}$ & $\begin{array}{c}\text { Amplitude } \\
(\mathrm{cm})\end{array}$ & $\begin{array}{c}\text { Phase } \\
(\text { days })\end{array}$ \\
\hline CNES/GRGS & $8.2 \pm 1.2$ & $99 \pm 9$ & $2.8 \pm 1.2$ & $162 \pm 13$ \\
\hline GLDAS & $3.2 \pm 0.3$ & $61 \pm 5$ & $0.2 \pm 0.3$ & $89 \pm 38$ \\
\hline CNES/GRGS-GLDAS & $6.4 \pm 1.3$ & $127 \pm 12$ & $2.9 \pm 1.3$ & $162 \pm 13$ \\
\hline
\end{tabular}


Table 3. Annual and semi-annual amplitudes and phases of the sinusoids best fitting to the monthly basin-averages of CSR GRACE, GLDAS and CSR GRACE derived WM (CSR-GLDAS) time series obtained after correcting the basin-average of CSR GRACE time series for the leakage signals. The results presented in this table are obtained from the scaled basin-average time series.

\begin{tabular}{|c|c|c|c|c|c|}
\hline \multirow{2}{*}{$\begin{array}{c}\text { Basin-average } \\
\text { Time Series }\end{array}$} & $\begin{array}{c}\text { Gaussian } \\
\text { Filter Half- } \\
\text { width (km) }\end{array}$ & $\begin{array}{c}\text { Amplitude } \\
(\mathrm{cm})\end{array}$ & $\begin{array}{c}\text { Phase } \\
\text { (days) }\end{array}$ & $\begin{array}{c}\text { Amplitude } \\
(\mathrm{cm})\end{array}$ & $\begin{array}{c}\text { Phase } \\
\text { (days) }\end{array}$ \\
\cline { 2 - 6 } & 0 & $10.7 \pm 1.8$ & $105 \pm 10$ & $2.5 \pm 1.8$ & $159 \pm 21$ \\
\cline { 2 - 6 } & 100 & $11.7 \pm 1.9$ & $104 \pm 10$ & $2.7 \pm 1.9$ & $160 \pm 21$ \\
\cline { 2 - 6 } CSR & 200 & $14.6 \pm 2.0$ & $101 \pm 8$ & $3.0 \pm 2.1$ & $161 \pm 20$ \\
\cline { 2 - 6 } & 300 & $19.3 \pm 2.4$ & $98 \pm 7$ & $3.3 \pm 2.4$ & $163 \pm 21$ \\
\cline { 2 - 6 } & 500 & $32.7 \pm 3.3$ & $96 \pm 6$ & $3.7 \pm 3.4$ & $165 \pm 27$ \\
\cline { 2 - 6 } & 0 & $4.8 \pm 0.4$ & $67 \pm 5$ & $0.4 \pm 0.4$ & $124 \pm 29$ \\
\cline { 2 - 6 } & 100 & $5.7 \pm 0.5$ & $68 \pm 5$ & $0.5 \pm 0.5$ & $122 \pm 28$ \\
\cline { 2 - 6 } & 300 & $8.3 \pm 0.6$ & $69 \pm 4$ & $0.7 \pm 0.6$ & $118 \pm 25$ \\
\cline { 2 - 6 } & 500 & $12.7 \pm 0.8$ & $70 \pm 4$ & $1.1 \pm 0.8$ & $115 \pm 23$ \\
\hline \multirow{5}{*}{ GLDAS } & 0 & $7.4 \pm 1.9$ & $129 \pm 15$ & $2.4 \pm 1.9$ & $164 \pm 23$ \\
\cline { 2 - 6 } & 100 & $7.7 \pm 1.9$ & $129 \pm 15$ & $2.6 \pm 2.0$ & $165 \pm 22$ \\
\cline { 2 - 6 } & 200 & $8.5 \pm 2.2$ & $131 \pm 15$ & $3.0 \pm 2.2$ & $168 \pm 21$ \\
\cline { 2 - 6 } & 300 & $10.0 \pm 2.6$ & $135 \pm 15$ & $3.5 \pm 2.6$ & $172 \pm 21$ \\
\cline { 2 - 6 } & 500 & $14.3 \pm 3.7$ & $143 \pm 15$ & $4.6 \pm 3.7$ & $178 \pm 23$ \\
\hline
\end{tabular}

Table 4. Temporal correlations and RMS differences between JASON-1 derived basin-average WM and CSR GRACE derived scaled basin-average WM time series (CSR-GLDAS) obtained after applying P4M6 decorrelation filter and Gaussian filters of varying half-widths.

\begin{tabular}{|c|c|c|}
\hline $\begin{array}{c}\text { Half-width of } \\
\text { Gaussian Filter } \\
(\mathrm{km})\end{array}$ & $\begin{array}{c}\text { Temporal } \\
\text { Correlation }\end{array}$ & RMS (cm) \\
\hline 0 & 0.87 & 4.79 \\
\hline 100 & 0.87 & 4.86 \\
\hline 200 & 0.88 & 5.26 \\
\hline 300 & 0.88 & 6.34 \\
\hline 500 & 0.86 & 10.51 \\
\hline
\end{tabular}


Table 5. Annual and semi-annual amplitudes and phases of the sinusoids best fitting to the monthly

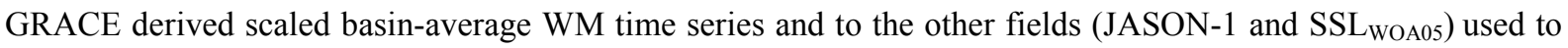
obtain Jason-1 derived basin-average WM time series.

\begin{tabular}{|c|c|c|c|c|}
\hline \multirow{2}{*}{$\begin{array}{c}\text { Basin-average WM Time } \\
\text { Series }\end{array}$} & \multicolumn{2}{|c|}{ Annual Signal } & \multicolumn{2}{c|}{ Semi-annual Signal } \\
\cline { 2 - 5 } & $\begin{array}{c}\text { Amplitude } \\
(\mathrm{cm})\end{array}$ & $\begin{array}{c}\text { Phase } \\
(\text { days })\end{array}$ & $\begin{array}{c}\text { Amplitude } \\
(\mathrm{cm})\end{array}$ & $\begin{array}{c}\text { Phase } \\
(\text { days })\end{array}$ \\
\hline JASON-1 & $6.8 \pm 1.1$ & $171 \pm 9$ & $2.2 \pm 1.1$ & $179 \pm 14$ \\
\hline SSL WOA05 $_{\text {JASON-1 derived WM }}$ & $2.2 \pm 0.9$ & $246 \pm 23$ & $0.7 \pm 0.9$ & $69 \pm 35$ \\
\hline CNES/GRGS - GLDAS & $6.5 \pm 1.4$ & $152 \pm 12$ & $2.8 \pm 1.4$ & $174 \pm 14$ \\
\hline CSR $^{*}$ - GLDAS* & $7.4 \pm 1.9$ & $127 \pm 12$ & $2.9 \pm 1.3$ & $162 \pm 13$ \\
\hline \multicolumn{3}{|r|}{}
\end{tabular}

* CSR solutions and the corresponding GLDAS model outputs are truncated to degree and order 50, decorrelated by P4M6 filter and no Gaussian smoothing is applied. 


\section{FIGURES}

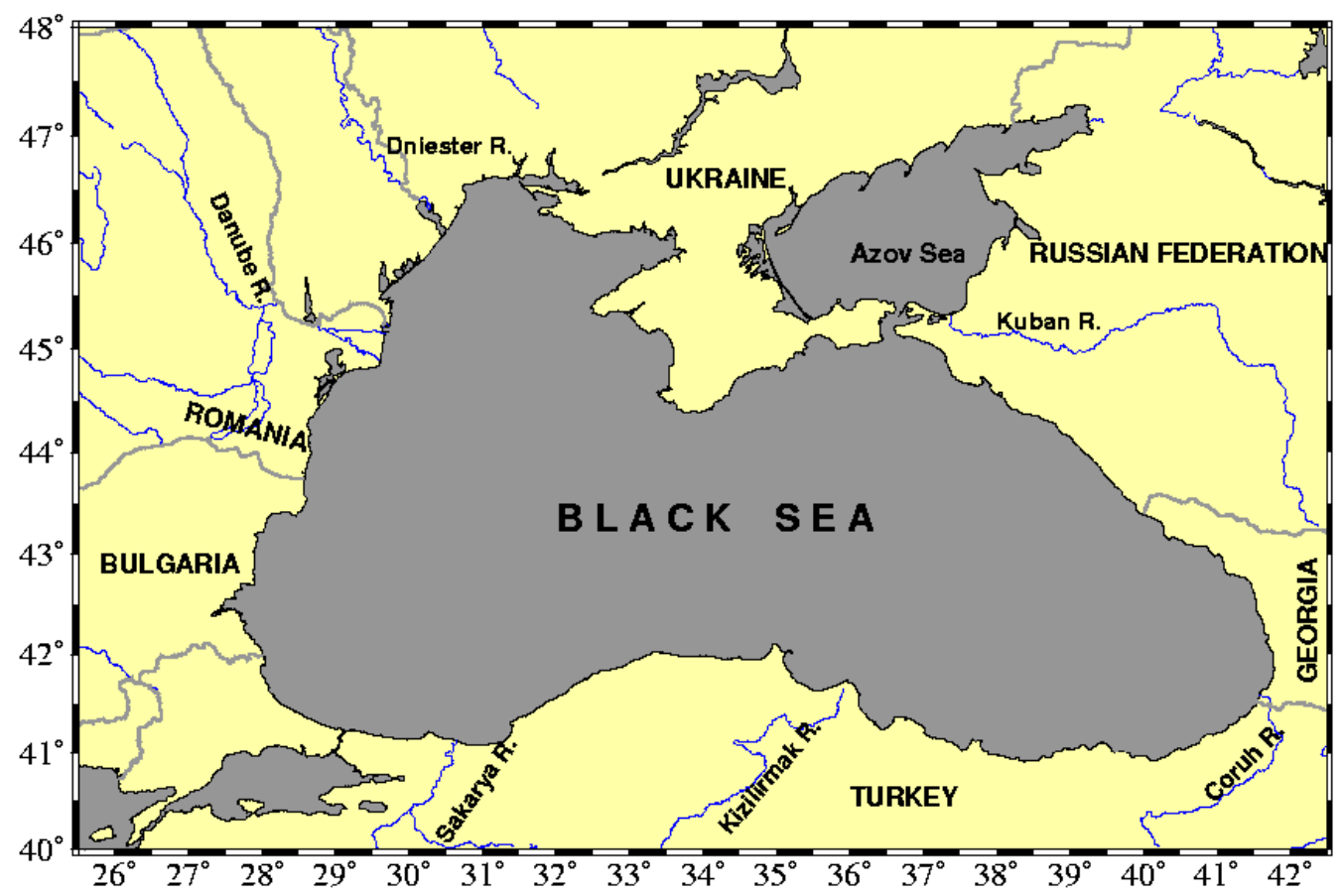

Figure 1

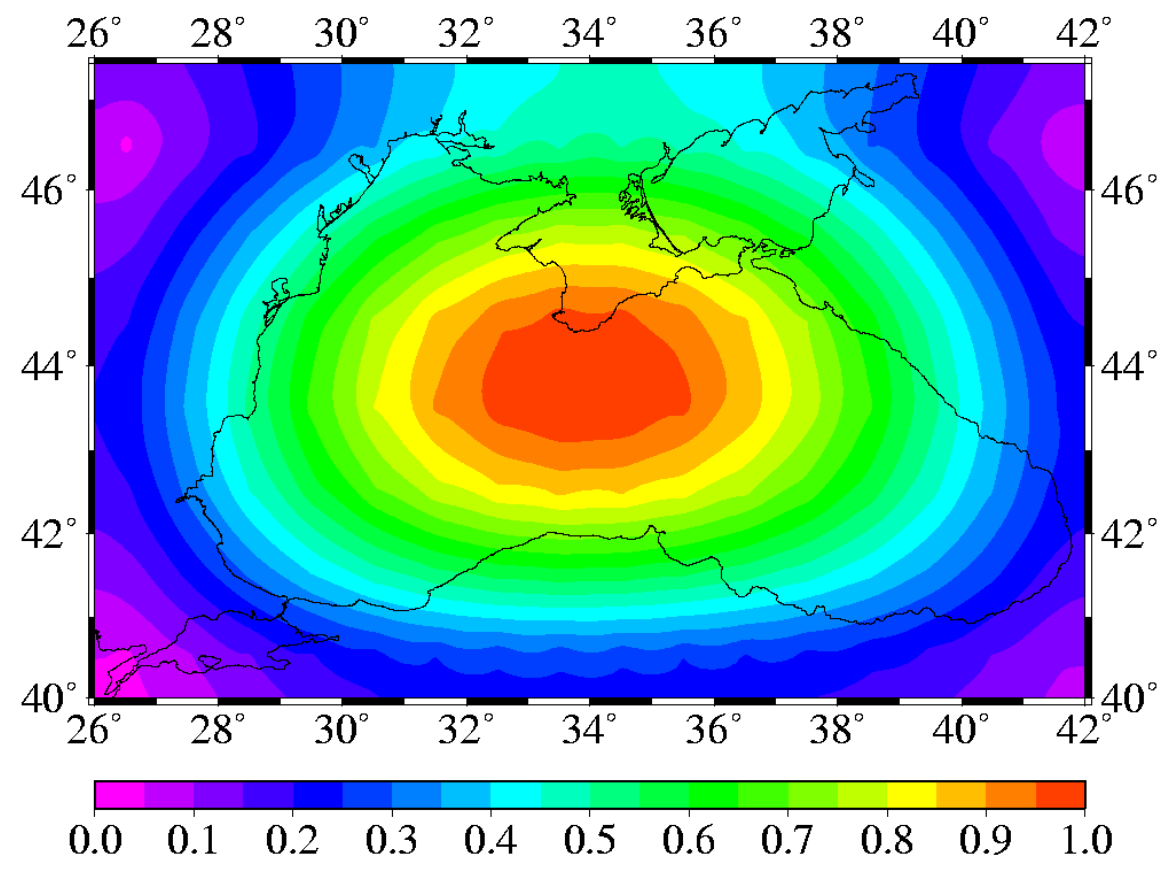

Figure 2 


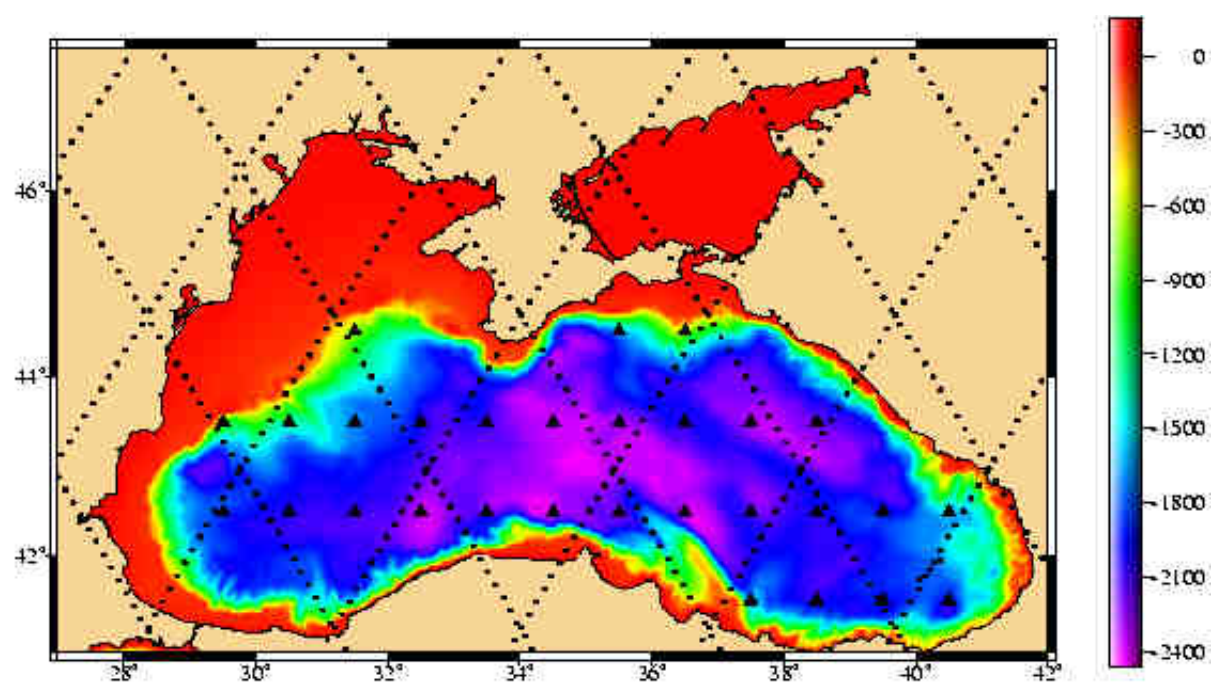

Figure 3

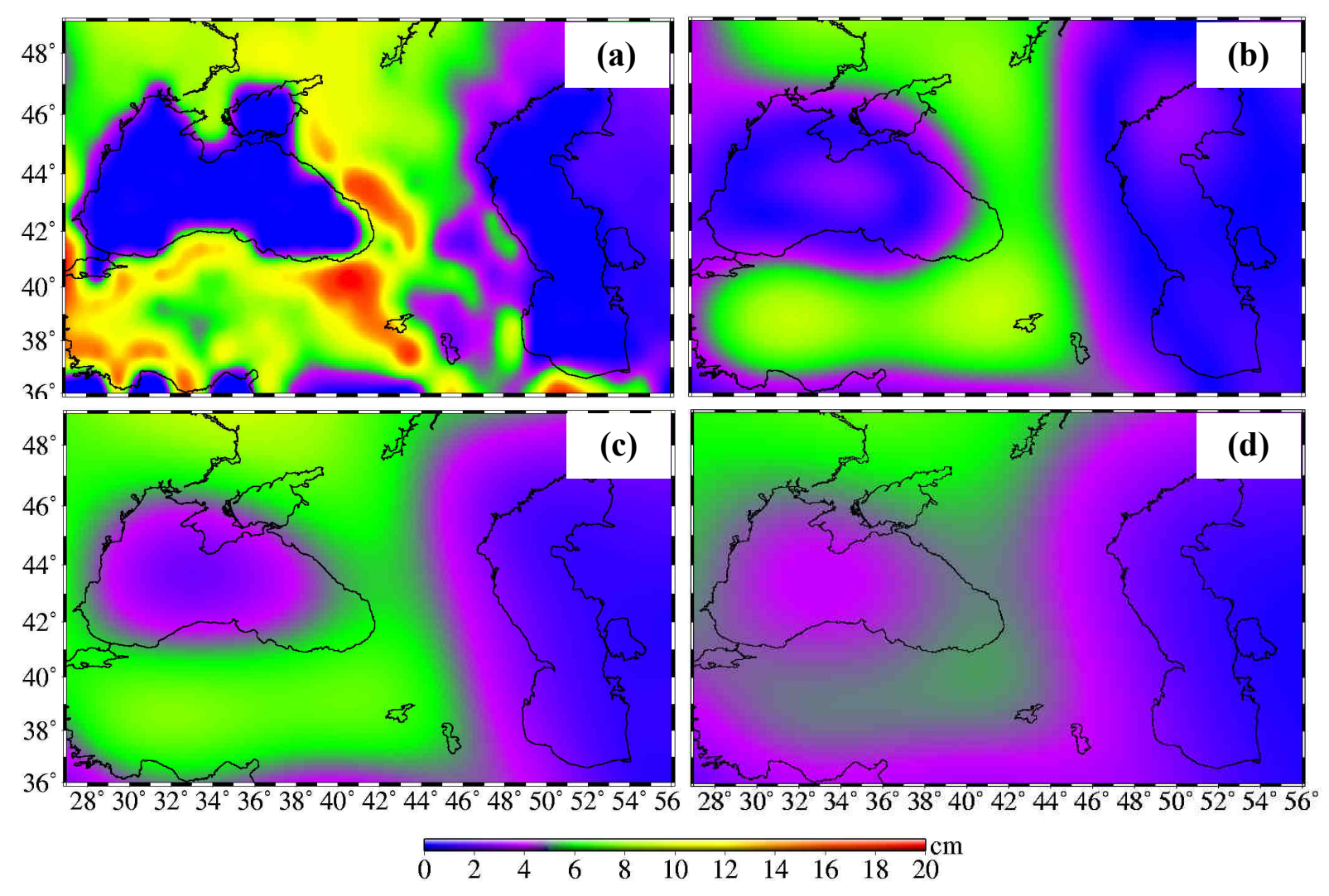

Figure 4 


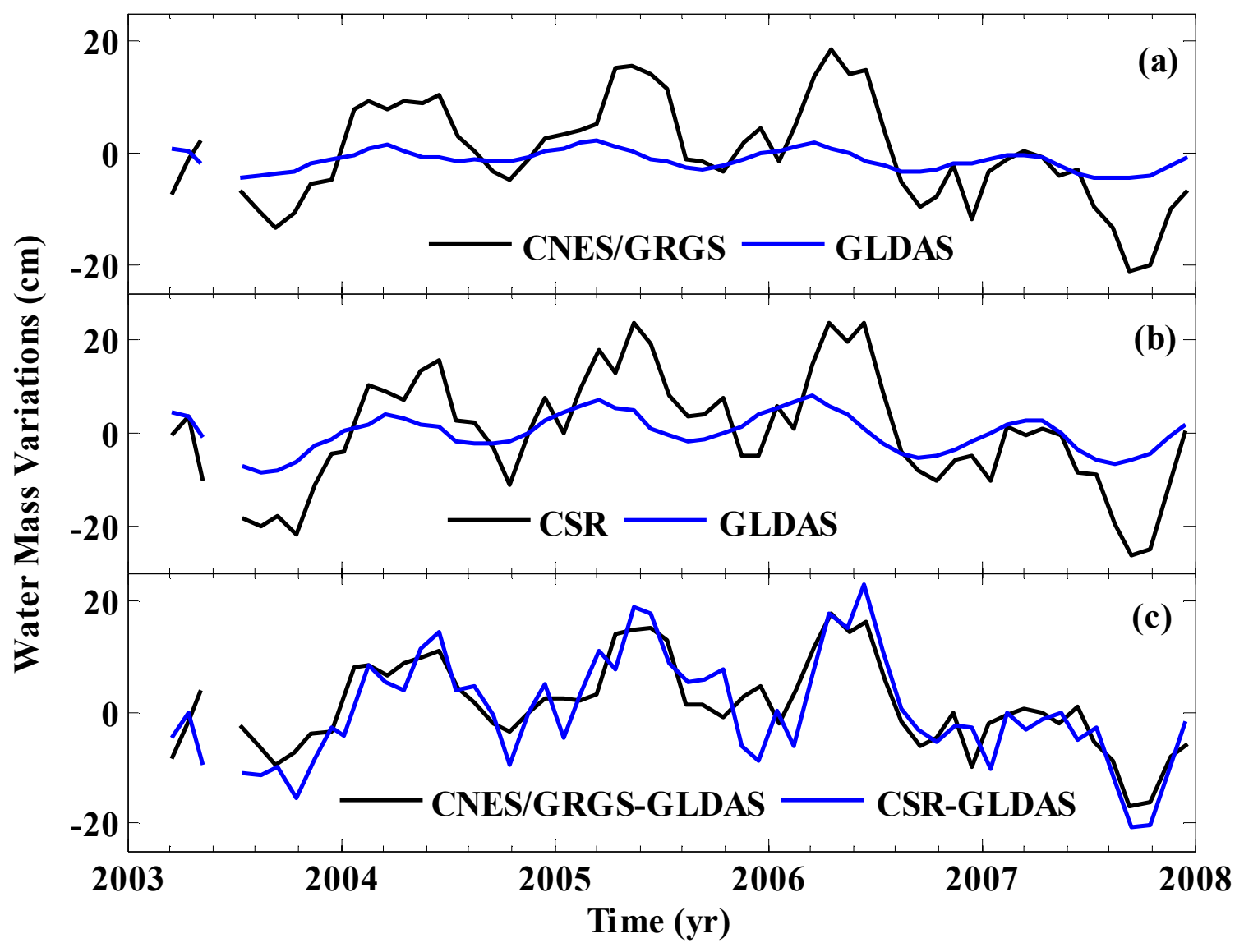

Figure 5 


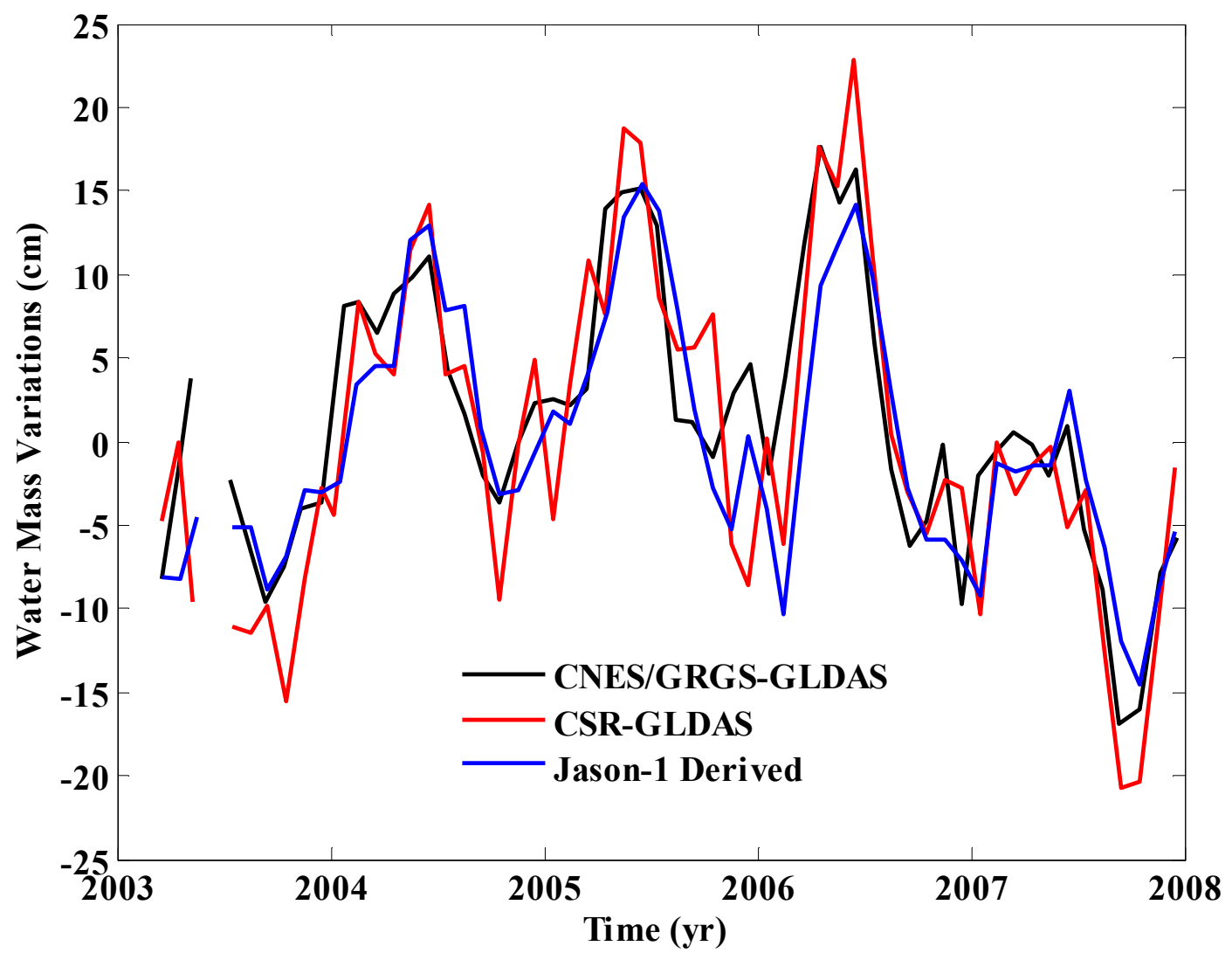

Figure 6 